\title{
Study on Supercharging Effect in Artillery Recoil Mechanism and the Effects
}

\author{
C. Wang*, P. L. Zhang, G. Q. Ren, Z. F. Gu \\ Department of Artillery Engineering, Ordnance Engineering College, Shijiazhuang 050003, China \\ Email: wchqcn@sohu.com
}

\begin{abstract}
Recoil mechanism is an important part of artillery. By pushing the liquid through the throttle at high speed, it can create a resisting force and dissipate the recoil energy. Liquid leaking is the most common fault of it. Because the body case of it is a sealed steel cylinder, liquid leaking will form a vacuum cell in the working chamber. Then this vacuum cell will cause an "effect of supercharging" in it when the artillery firing. This will bring about many disadvantage effects to the artillery, especially to the performance of motive seals. Usually the liquid leaking rate is used to evaluate the seals tightness of the recoil mechanism. However considering the liquid leaking and the "effect of supercharging", an interesting thing will be found that the liquid leaking rate as the only evaluation criterion becomes not enough.

This paper is mainly concerned with the "effect of supercharging" in artillery recoil mechanism caused by liquid leaking and its effect to the motive seals. Based on properties, the liquid leaking was divided into static liquid leaking, adhesion liquid leaking and gap liquid leaking. Their special mechanisms and characters were introduced. The mathematic model for the liquid leaking in the process of recoil mechanism working was presented. Using this model, we analyzed the reason why the pressure in artillery recoil mechanism mounted up when the liquid leaking took place. Then the working chamber pressure in different leakages was calculated. Through the pressure-leakage curve, confirmed the judgment that liquid leaking could cause the "effect of supercharging" in the working chamber of recoil mechanism. Researched the hazards of the supercharging to different types of recoil mechanism seals. The theories in this article are valuable to recoil mechanism seals design and performance evaluation.
\end{abstract}

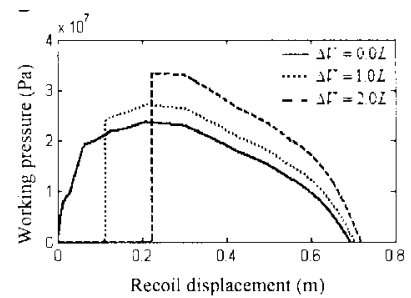

Figure: Working pressures in different leakages

\section{REFERENCES}

1. Gao SZ, Chen YS, Zhang YL, Zheng JG. Artillery recoil mechanism design. Armament Science, 1995; 102-114

2. Y Xi. Foundation of sealing device design. Science Technology, 1987; 94-103

3. Song PY. Mechanism of soft packing seal. Lubrication and Sealing, Vol.2, 2000; 64-66 